Brit. Heart $\mathcal{F} ., 1967,29,457$.

\title{
Fatal Fungal Infection Following Open-heart Surgery
}

\author{
S. W. B. NEWSOM*, W. R. LEE†, AND J. RUSSELL REES
}

From The Departments of Bacteriology, Morbid Anatomy, and Cardiology, Westminster Hospital, London, S.W.1

It is now common practice to give large doses of antibiotics, usually in combination, to patients undergoing open-heart surgery. As a result the risks of bacterial infection have been much reduced. There remains, however, a hazard of fungal infection at the operation site in the heart or great vessels, with disseminated lesions following arterial embolism.

Since 1956, 19 such cases have been reported following open-heart surgery (Sanger et al., 1962; Jamshidi, Pope, and Friedman, 1963; Simmons and Turner, 1963; Newman and Cordell, 1964; Uys et al., 1963; Climie and Rachmaninoff, 1965). Because of the difficulties in diagnosis we report a further case.

\section{Clinical History}

A young woman, aged 20 when she died, was known to have a murmur since the age of 5 . In 1964, when admitted to the Westminster Hospital, she was symptom free, apart from infrequent substernal pain related to exertion.

There were signs of aortic valve stenosis, and cardiac catheterization showed a mean valve gradient of $42 \mathrm{~mm}$. Hg. Calculated aortic valve area was $0.71 \mathrm{~cm}^{2}(0.41$ $\left.\mathrm{cm} .{ }^{2} / \mathrm{m} .{ }^{2}\right)$. Because of the severity of the stenosis, aortic valvotomy was done by Mr. C. E. Drew in May 1964 under profound hypothermia. A small aortic incision was made; the valve cusps were found to be grossly thickened and slightly calcified, with fusion of two of the aortic commissures. The stenosis was relieved and the aortic incision closed in two layers. Recovery was rapid, though post-operative fever reached $38^{\circ} \mathrm{C}$. $\left(101^{\circ} \mathrm{F}\right.$.) on the fourth day, disappearing finally on the 15th day after operation.

For 2 days before the operation she had been given $250 \mathrm{mg}$. erythromycin q.d.s. orally. One mega unit

\footnotetext{
^ Present address: Papworth Hospital, Papworth Everard, Cambs.

† Present address: Western Infirmary, Glasgow.
}

penicillin $G$ and $0.5 \mathrm{~g}$. streptomycin were given intramuscularly b.d. for 10 days following valvotomy. She was discharged feeling well on the 26th day.

In August 1964, because of severe dental pain, four fillings were renewed. No teeth were extracted and no antibiotics were given. In September, while on holiday, she was immobilized for about two weeks by severe pain in the left leg. On Christmas Eve she developed similar pain in the right leg and on the next day she was admitted to her local hospital with epileptic fits. There was a misleading family history of epilepsy.

After this her health deteriorated. She suffered intermittent claudication in the right leg, lost weight, and experienced frequent bouts of fever and sweating. Finally in July 1965 she developed painful lumps in the finger tips, and sudden severe pain across the lower back.

On readmission to Westminster Hospital, she looked ill and had generalized pigmentation. There was no purpura, Hess's test was negative, the spleen was not palpable, and there was no finger clubbing. The cardiac signs were unchanged but arterial pulsation in the right leg was absent. Femoral dissection or embolus was postulated. A diagnosis of endocarditis was made, but many blood cultures were negative over the next 10 days, during which time she had a low intermittent fever without change in the physical signs.

She was given $500 \mathrm{mg}$. ampicillin q.d.s. orally and her fever subsided temporarily. However, her back pain increased and she developed pain in the left hip. $X$-ray films, previously negative, now showed destruction of the 9 th and 10th thoracic vertebræ and of the acetabular rim on the left.

Treatment was changed to 12 mega units penicillin G and 1 g. streptomycin intramuscularly each day in divided doses. The fever and bone pain persisted despite immobilization in a plaster bed. $500 \mathrm{mg}$. fusidic acid t.d.s. orally was therefore substituted, but she became worse, with crops of hæmorrhages beneath the nails and conjunctivæ. After 10 days of this antibiotic a dense left hemiparesis occurred and treatment was changed to $250 \mathrm{mg}$. chloramphenicol q.d.s. orally without effect. She developed signs of a saddle embolus at the aortic bifurcation, and, after two 457 


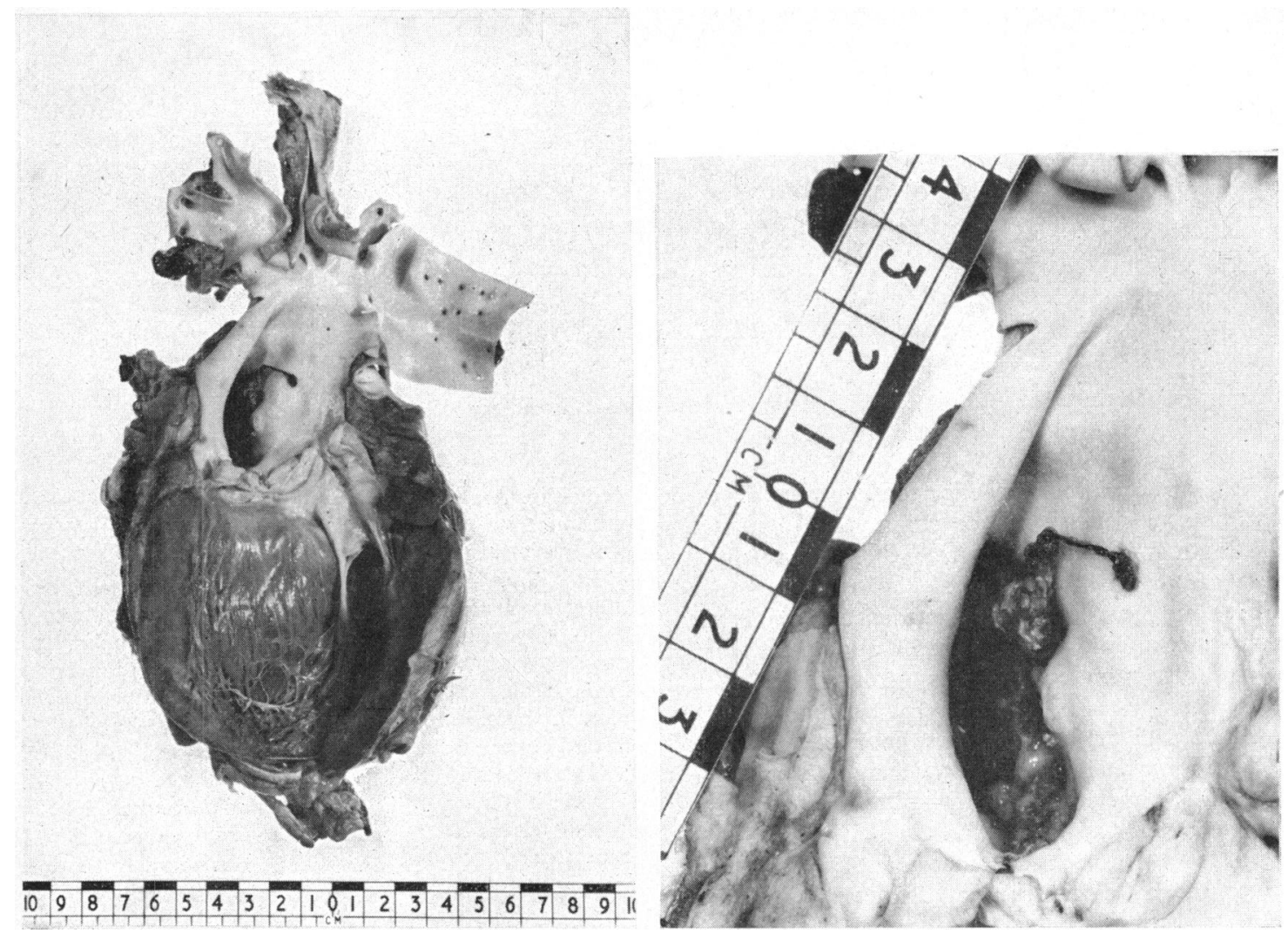

Fig.-View of the left ventricle and aorta with close-up of the entrance to the aneurysm.

Throughout there were no changes in $x$-ray appearances of the heart nor in her electrocardiographs. The murmurs were unaltered, finger clubbing never appeared, and numerous blood cultures up to the end of her illness were sterile.

\section{Laboratory Findings}

Ten blood cultures and an iliac crest marrow culture were done before starting therapy. The blood was inoculated into glucose broth and two pour plates made with nutrient agar, one of which was incubated ærobically with $\mathrm{CO}_{2}$ and the other anærobically. Cultures were also made in Brewers medium and Robertson's meat broth, and a guinea-pig was inoculated intraperitoneally with $1 \mathrm{ml}$. blood. All the cultures remained sterile during 15 days of incubation. Results later in the disease were similar.

The oral flora early in the disease was normal, but Candida albicans grew from a swab taken after three weeks' antibiotic therapy, and was thought to be a result of treatment. A high vaginal swab taken three days before death also grew candida.

The antistreptolysin $O$ titre was less than 50 units throughout, and a complement-fixation test for $Q$ fever was negative. The serum contained increased levels of agglutinins for Salmonella paratyphi B.O. (1/320-1/640) and non-specific salmonella $H(1 / 80-1 / 320)$, while the anti paratyphi B.H. level was normal. The significance of this is unknown but cultures of urine and fæces were negative. The brucella agglutinin tests were negative. Urine deposits were normal except for one examined 2 days before death which contained scanty candidas.

The blood count remained surprisingly normal during her illness, an average value for the leucocytes being 9800 with a normal differential count. The bonemarrow was normal. The blood sedimentation rate (Wintrobe) was raised to $50 \mathrm{~mm}$. in the first hour, and serum $\gamma$-globulin levels were raised.

\section{Findings at Necropsy}

There was a mycotic aneurysm at the site of the aortic incision, which was infected with fungus. The aneurysm was generally $4 \mathrm{~cm}$. deep but extended behind the aorta and had an orifice $4 \mathrm{~cm}$. in diameter. The sac contained a silk suture, chocolate-coloured pus, blood clot, and firm nodular yellow material (Fig.). The left ventricle was enlarged. The aortic valves were thickened, but no longer stenosed, and none of the valves showed endocardial vegetations.

The lower abdominal aorta, the iliac arteries, and the femoral arteries contained ante-mortem thrombus similar to the material in the false aneurysm. 
The spine contained extensive necrotic areas from the 9 th thoracic to the 4 th lumbar vertebræ. There was acute purulent arthritis of the left hip joint, with erosion of cartilage and destruction of subchondral bone.

The spleen and kidneys showed numerous infarcts, and the right lentiform nucleus and internal capsule of the brain had been destroyed by recent hæmorrhage.

Histology. Fungal hyphæ were found in clumps throughout the aortic aneurysm. Fungi were also found in those arteries that contained thrombus, and in the liver, spleen, and spine. The hyphæ were septate with lateral branching when stained by the Gridley method; and spore forms were numerous. These are the characteristic appearances of Candida albicans (Zimmerman, 1950).

Candida albicans was cultured from numerous sites and identified by its characteristic sugar fermentations and its ability to form germ tubes in serum.

\section{Discussion}

The clinical course was suggestive of endocarditis yet there were several unusual features. Throughout her long illness there was no increase in aortic reflux as judged by the murmur, the arterial pulse, and the heart size. This suggested that the aortic valve was probably not the site of infection. The disease differed also from most cases of bacterial endocarditis in the absence of leucocytosis and of finger clubbing. The arterial emboli were surprisingly large, and the bone lesions were also unusual.

Combined with these features, the failure of penicillin G, streptomycin, fusidic acid, and chloramphenicol to affect the disease pointed to fungal infection at the aortic incision, but we were reluctant to make this diagnosis without confirmatory blood cultures.

The failure to grow the fungus was a puzzling and interesting point. The organism has been recovered in 75 per cent of the recorded cases of candida endocarditis following operation, but not in the single case with a similar aortic aneurysm reported by Sanger et al. (1962). An artificial blood culture done by adding a small inoculum of the candida from our patient to fresh blood and culturing it in the usual way was positive, and the type of glucose broth used had been previously successful in the growth of candida from two cases of disseminated candidiasis (Lewin, 1963).

Louria and Brayton (1964) showed that fresh serum was bacteriostatic for candida; however, viable counts made after exposing identical numbers of the yeasts to normal serum and to our patient's serum for one hour revealed no differences in their fungistatic activities.
We conclude from this that the media used would have supported the growth of the candida, and that the negative blood cultures were due to the absence of fungæmia, despite occasional release of large fragments containing mycelia from the aneurysm.

An ante-mortem specimen of serum was investigated to decide whether serological diagnosis would have been possible. This serum agglutinated a formalinized suspension of the organism at a titre of $1 / 128$, whereas 12 normal sera had a titre of $1 / 16$ or less. The serological titres were not recorded in the previous cases. Winner (1955) investigated 2017 sera using an agglutination reaction, and found no significant difference between controls and patients with local moniliasis; only 5 of his sera (4 patients and 1 control) had titres of greater than 1/64. Comaish, Gibson, and Green (1963), however, correlated agglutinin titres of 1/64 and above with candida infection. Stallybrass (1964) demonstrated precipitins to a formamide extract of candida in the serum of a patient with disseminated moniliasis, and suggested that this might be a diagnostic test, but none were found in our patient.

Though $x$-ray films failed to reveal the mycotic aneurysm, a fungal infection of the aortic incision was likely on clinical grounds. We should not have been deterred by the sterile blood cultures during dissemination of the infection. The case suggests that estimation of the agglutinin titre against candida may be helpful, but that a firm diagnosis may only be made, in some instances, by examination of the emboli. Though cure of fungal endocarditis after heart surgery has only once been reported (Sanger et al., 1962), candida is sensitive to amphotericin B, and the earlier this is given, the better the chance of success.

\section{Summary}

A patient with congenital aortic valve stenosis is described in whom valvotomy was followed by fatal candida infection of an aneurysm at the aortic incision.

A febrile illness with large arterial emboli began four months after operation with metastatic infection of the spine, hip, and brain. Death occurred one year after onset.

Blood cultures were repeatedly sterile, despite widespread embolization of clot containing mycelia. There was a raised agglutinin titre against Candida albicans. This finding may be of diagnostic help when repeated blood cultures are sterile.

We are very grateful to Dr. C. J. Gavey and Mr. C. E. Drew for permission to publish this case and to Professor B. W. Lacey for his suggestions concerning agglutinin tests. 


\section{References}

Climie, A. R. W., and Rachmaninoff, N. (1965). Fungal (Candida) endocarditis following open-heart surgery. F. thorac. cardiovasc. Surg., 50, 431.

Comaish, J. S., Gibson, B., and Green, C. A. (1963). Candidiasis-serology and diagnosis. $\mathcal{F}$. invest. Derm., 40, 139.

Jamshidi, A., Pope, R. H., and Friedman, N. H. (1963). Fungal endocarditis complicating cardiac surgery. Arch. intern. Med., 112, 370.

Lewin, K. (1963). Two cases of monilial septicæmia, secondary to carcinoma of the mouth, treated successfully with intravenous amphotericin B. Postgrad. med. F., 39, 359.

Louria, D. B., and Brayton, R. G. (1964). A substance in blood lethal for Candida albicans. Nature (Lond.), 201, 309.
Newman, W. H., and Cordell, A. R. (1964). Aspergillus endocarditis after open-heart surgery. $\mathcal{F}$. thorac. cardiovasc. Surg., 48, 652.

Sanger, P. W., Taylor, F. H., Robicsek, F., Germuth, F. Senterfit, L., and McKinnon, G. (1962). Candida infection as a complication of heart surgery. F. Amer. med. Ass., 181, 88.

Simmons, N. A., and Turner, P. (1963). Candida endocarditis after cardiac surgery. Brit. med. F., 2, 1041.

Stallybrass, F. C. (1964). Candida precipitins. F. Path. Bact., 87, 89.

Uys, C. J., Don, P. A., Schrire, V., and Barnard, C. N. (1963). Endocarditis following cardiac surgery due to the fungus Paecilomyces. S. Afr. med. F., 37, 1276.

Winner, H. I. (1955). A study of Candida albicans agglutinins in human sera. F. Hyg. (Lond.), 53, 509.

Zimmerman, L. E. (1950). Candida and aspergillus endocarditis. Arch. Path., 50, 591. 